\title{
IDENTIFICATION AND EVALUATION OF INTERNAL LOGISTICS RISKS WITHIN METALLURGICAL SUPPLY CHAIN
}

\author{
Martin SVÁČEK, Radim LENORT \\ VSB - Technical University of Ostrava, Faculty of Materials Science and Technology, Ostrava, \\ Czech Republic, EU, martin.svacek.st@vsb.cz, radim.lenort@vsb.cz
}

https://doi.org/10.37904/metal.2021.4296

\begin{abstract}
The aim of this article is to identify the main risks in internal logistics processes in companies involved in metallurgical supply chains. The article also includes an initial proposal on how to work with and eliminate some risks. The main emphasis is on the evaluation of the internal logistics risks in "plan - production" chain. The methodological basis was a questionnaire survey and semi-structured interviews in selected metallurgical and related companies. The risks were identified and assessed in nine companies in different part of metallurgical supply chains.
\end{abstract}

Keywords: Internal logistics processes, logistics risks, metallurgical supply chain

\section{INTRODUCTION}

In recent years, companies have seen an increase in many risky events, which subsequently disrupted logistics flows. These situations are the result of a large set of factors that need to be recognized and understood that risks in logistics arise not only outside but also inside company. The resulting side effects in any link in the logistics chain can spread and can subsequently affect the entire chain. It is therefore very important to identify, analyze and deal with the logistics risks in an appropriate way. Any risks incurred can therefore be defined as non-standard events that are likely to disrupt the smooth logistics flows.

From the point of view of the future definition of logistics risks, we are therefore convinced that the following are most likely to occur:

- does not meet the customer's requirements, especially in terms of time, quantity, quality and location,

- compliance will be ensured at the expense of flow efficiency,

- the existing logistical potential is not fulfilled,

- $\quad$ there will be a non-standard use of the process, which will subsequently affect the standard flow - the creation of a precedent,

- $\quad$ there is a financial loss at the expense of a non-standard procedure at the level of logistics, but also business costs.

As part of long-term practice in various industries, the authors became convinced that the risk management process within internal logistics is not properly grasped and is not given sufficient importance. A general view based not only on practical experience, but also on the basis of discussions within the logistics community shows that all risk factors are perceived as external pressures and less reference is made to the internal environment of industrial companies.

A clear indicator of this experience is also the recent global threat COVID-19, when companies were able to respond to external influences, such as setting safety stocks, hygiene aids, shift distribution, remote work, but failed to work effectively with internal process risks. Such internal risks identified by the pandemic included, for example: 
- insufficiently erudite workers within the IS,

- incorrectly set processes,

- inappropriate procedures,

- incorrectly set information flow.

The subject of the article is therefore the area of internal logistics risks in a metallurgical enterprise and in enterprises with subsequent processing and their occurrence within the main and supporting logistics processes. The article also includes an initial proposal on how to work with and eliminate some risks. The article does not have the ambition to solve all logistics processes of companies, the main attention is paid to the logistics chain shown in Figure 1. It is the chain starting with the planning of material and capacity requirements and ending with the supply of production processes. The actual production and subsequent distribution logistics processes were no longer the subject of the research. The aim of this article is to identify the main risks in mentioned internal logistics chain in companies involved in metallurgical supply chains.

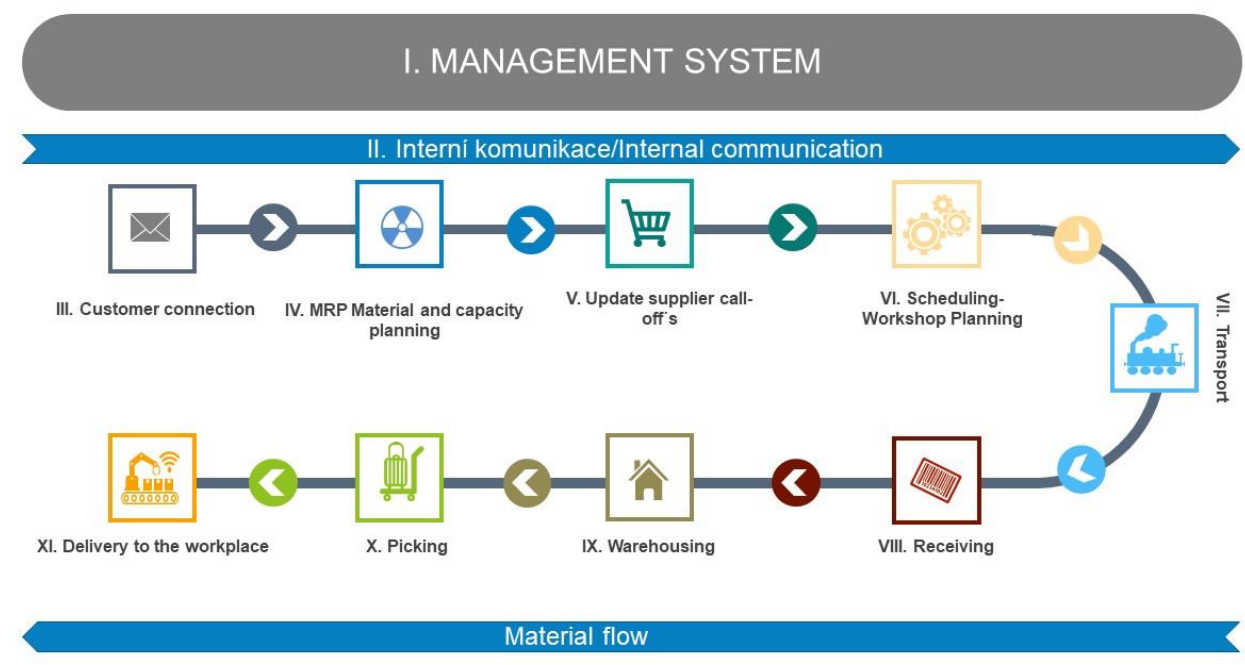

Figure 1 Definition of the subject of research from logistics chain point of view

\section{LITERATURE REVIEW}

Currently metallurgical companies operate in a rapidly changing complex environment. Increasingly, their competitiveness depends on complex networks of partners, both in the supply chain, i.e. in terms of delivering goods and services in the right quantity, at the right time and in the right place, and under constant pressure on costs and quality. Similarly, companies are increasingly using sophisticated logistics strategies such as lean manufacturing and global resources to maintain a competitive advantage [1]. The rapidly changing complex environment and complicated logistics strategies of companies contribute to a higher level of vulnerability and risk in the logistics chain. As a result, organizations are increasingly exposed to unexpected influences that affect the entire operation of the logistics chain.

Therefore, the need for a common approach to risk management is increasingly emphasized in the current literature and the key to achieving this goal is to facilitate supply chain integration [2]. An integrated supply chain is achieved by extending the scope of management inside and outside the company, involving suppliers and customers [3]. In-house integration enables the circulation of risk information between departments within the company, while inter-company integration improves the exchange of information between supply chain partners and helps them stay alert and respond quickly to disruptions through information sharing and coordinated operations [4]. Companies must therefore facilitate integration within and between companies in order to facilitate effective risk management throughout the supply chain. 
Metallurgical companies face uncertainty at all levels of their business processes in the supply chain, and this uncertainty can negatively and positively affect the company's goals. If a company has a sound framework for identifying and assessing risks, it can manage risks arising at any level [5], distinguishing between internal and external risks. Zhao et al. [6] classify supply chain risk into three categories: internal risks, supply-based risks and demand-based risks. Internal risks are risks that occur within companies and can be divided into two levels - strategic and operational. Strategic risk is associated with corporate policies and decisions [7,8]. Conversely, operational risks are associated with the day-to-day running of the company, such as machine failure, lead times, IT problems, human error and technological change [9]. Internal integration refers to the degree to which a company structures its own organizational strategies, procedures and processes for collaboration, synchronized processes to meet the requirements of its customers and to work effectively with its suppliers [10]. Risk management in the logistics chain refers to a coordinated approach of members of the whole chain to identify and manage risk in the internal chain in order to reduce the vulnerability of the chain. Such an approach is developed through the adoption of various risk management procedures, which include the basic aspects of risk identification, assessment of risk sources, monitoring and risk mitigation throughout the logistics chain [11].

\section{RESEARCH RESULTS}

The aim of the research was to derive directions based on the knowledge of the causes of internal risks, which should be followed by the methodology of internal logistics management in order to increase the very resilience of the entire internal chain to internal and external influences.

A questionnaire survey and semi-structured interviews were used to identify critical internal logistics risks. The questionnaire is structured into primary risk areas, which correspond to the analyzed part of the internal logistics chain. The separate areas then reflect the partial risks that occur in companies. Within the questionnaire and semi-structured interviews, individual respondents comment on the severity of the risk in the form of a subjective point scale, where 5 expresses the worst risk and 1 then the lowest risk.

In order to obtain answers to the defined questions, the address of a group of companies focused on metallurgical production and their subsequent use in the production process was applied. Companies from the demand side of metallurgical supply chains was selected to have also metallurgical or material processing production (see Table 1).

Table 1 Respondents

\begin{tabular}{|c|c|c|}
\hline Company & Branch of business & $\begin{array}{c}\text { Metallurgical and material processing } \\
\text { related scope of business (according to } \\
\text { Czech law) }\end{array}$ \\
\hline TŘINECKÉ ŽELEZÁRNY, a. s. & Metallurgy & Foundry, forging, galvanization, machining \\
\hline BONATRANS GROUP a.s. & Metallurgy, Engineering & Foundry, forging, machining \\
\hline Vyncke s.r.o. & Engineering & Machining \\
\hline TATRA TRUCKS a.s. & Automotive & Foundry, forging, metalworking, galvanization \\
\hline ŠKODA AUTO a.s. & Automotive & Galvanization, machining \\
\hline Brose CZ spol. s r.o. - plant I & Automotive & Galvanization, machining \\
\hline Brose CZ spol. s r.o. - plant II & Automotive & Galvanization, machining \\
\hline $\begin{array}{c}\text { Brose México, S. A. de C. V. } \\
\text { Sodecia Safety \& Interiors }\end{array}$ & Automotive & - \\
\hline Leskovec, s.r.o. & Automotive & \\
\hline
\end{tabular}


The questionnaire contained 11 questions. The input logic for formulating the questions was 9 specified areas of internal logistics, see the Figure 1. Each of the sections was elaborated into the card itself and was divided into sub-questions. Closed questions prevailed, but with the possibility of written additions. Data collection was performed in the second half of 2020 and in the first quarter of 2021. The data were grouped and the individual responses revealed three main risk areas:

1) Material and capacity planning -3.67 average numbers of points of the logistics risk severity. As the main risks were identified: (a) Customer request change last minute (75\%), (b) Insufficient communication (13\%), (c) EDI data upload errors (12\%).

2) Customer connection -3.56 average numbers of points of the logistics risk severity. As the main risks were identified: (a) Planning outside of ERP system (57\%), (b) Inaccurate data (29\%), (c) Insufficient ERP settings (14\%).

3) Scheduling and workshop planning -3.56 average numbers of points of the logistics risk severity. As the main risks were identified: (a) Last minute changes (63\%), (b) Breakdowns (13\%), (c) Capacity (13 $\%)$, Other risks ( $11 \%)$.

All surveyed companies were involved in global logistics chains, which means that the international setting of internal logistics systems to meet international needs and be competitive prevails.

\section{DISCUSSION AND CONCLUSIONS}

Among the internal logistics risks, which the respondents mentioned according to their experience, were identified customer changes influencing the material and capacity planning, internal settings of the ERP system in form of planning outside the system and changes directly in the workshop. The conclusions of the individual answers lead to the main risk result, which leads to problems associated with planning from the perspective of both the external and subsequently the internal process.

Today's business is customer-driven, so it is no surprise that six out of nine respondents cited customer change as the biggest risk, which in turn affects internal processes. In this regard, the coordination of individual requirements is important. Not to perceive them as dogmatic, but to try to find a mutually satisfying path. Within the internal setup, this is the first and often one of the most important inputs for a smooth production plan. The correct setting and use of the information system leads to this coordination of individual requirements. Grouping individual requirements or partial production steps into larger production slots.

Quality planning and management in manufacturing companies is one of the basic prerequisites for success in today's competitive environment. Given the complexity of planning processes and the large number of parameters that affect this activity, anarchy does not pay off. Manage production processes more efficiently and monitor costs more consistently. Facilitate cooperation with subcontractors and business partners. All this brings the use of an information system which includes any planning system. Nowadays at least MRP II, but in the case of competitive struggle already APS.

If we have production well described by a technological process, it is possible to use computer technology to compile a plan. Production on production lines can be processed very well in information systems, where orders run immediately after each other (serial production) and line time is essential here. The moments that affect one's own planning are related to the complexity of the production technology used. In such a process, the process of setting, reprogramming or calibrating the production line is usually crucial.

A key advantage is the identification of the bottleneck through which the contracts pass. Then it is possible to make perfect use of this workplace by determining the order in which orders are passed. Other operations are planned around a key production process. So far, we have omitted an important part of the planning process - material planning. It is perfectly understandable that without material it is not possible to produce and its lack 
is critical for the completion of production on time. In order to ensure a timely and smooth delivery of the material, it is necessary to pay sufficient attention to ordering it.

\section{ACKNOWLEDGEMENTS}

The work was supported by the specific university research of Ministry of Education, Youth and Sports of the Czech Republic at VSB - Technical University of Ostrava, project no. SP2021/71.

\section{REFERENCES}

[1] BLOME, C., SCHOENHERR, T. Supply chain risk management in financial crises - a multiple case-study approach. International Journal of Production Economics. 2011, vol. 134, no. 1, pp. 43-57.

[2] LI, G., FAN, H., LEE, P.K.C., CHENG, T.C.E. Joint supply chain risk management: An agency and collaboration perspective. International Journal of Production Economics. 2015, vol. 164, pp. 83-94.

[3] GEARY, S., CHILDERHOUSE, P., TOWILL, D.R. Uncertainty and the seamless supply chain. Supply Chain Management Review. 2002, vol. 6, no. 4, pp. 52-61.

[4] LIU, C.-L., LEE, M.-Y. Integration, supply chain resilience, and service performance in third-party logistics providers. The International Journal of Logistics Management. 2018, vol. 29, no. 1, pp. 5-21.

[5] CHRISTOPHER, M., PECK, H. Building the resilient supply chain. International Journal of Logistics Management. 2004, vol. 15, no. 2, pp. 1-13.

[6] ZHAO, L., HUO, B., SUN, L., ZHAO, X. The impact of supply chain risk on supply chain integration and company performance: A global investigation. Supply chain management. 2013, vol. 18, no. 2, pp. 115-131.

[7] BURKI, U., ERSOY, P., NAJAM, U. Top management, green innovations, and the mediating effect of customer cooperation in green supply chains. Sustainability. 2019, vol. 11, no. 4, paper no. 1031.

[8] WU, G.C. The influence of green supply chain integration and environmental uncertainty on green innovation in Taiwan's IT industry. Supply Chain Management. 2013, vol. 18, no. 5, pp. 539-552.

[9] CHOPRA, S., SODHI, M.S. Managing risk to avoid supply-chain breakdown. MIT Sloan Management Review. 2004, vol. 46, no. 1, pp. 53-61.

[10] JÜTTNER, U., PECK, H., CHRISTOPHER, M. Supply chain risk management: outlining an agenda for future research. International Journal of Logistics: Research and Applications. 2003, vol. 6, no. 4, pp. 197-210.

[11] BODE, C., WAGNER, S.M., PETERSEN, K.J., ELLRAM, L.M. Understanding responses to supply chain disruptions: insights from information processing and resource dependence perspectives. Academy of Management Journal. 2011, vol. 54, no.4, pp. 833-856. 